\title{
Farklı ısınma aktivitelerinin 50 m yüzme performansı üzerine etkisi
} Ahmet Emre FAKAZLI ${ }^{1}$, İpek EROĞLU KOLAYIŞ ${ }^{2}$

\begin{abstract}
$\ddot{\mathbf{O} z}$
Bu çalışmada 3 farklı 1sınma aktivitesinin yüzücülerde $50 \mathrm{~m}$ serbest stil performansı üzerine etkisi incelenmiştir. Çalışmaya toplamda 17 (5 kı, 12 erkek) sporcu (yaş:13 $\pm 0,99$, Spor

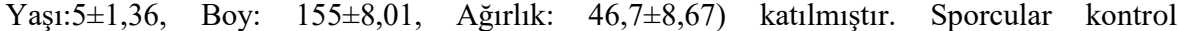
uygulamasında, 5dk hafif tempo koşu ardından 2dk yürüyüş ve 1sınma amaçlı 60x50m serbest stil yüzme ardından herhangi bir statik germe ya da dinamik 1sınma hareketi gerçekleştirilmemiştir. Performans öncesinde 3dk toparlanma süresi verilmiştir. Ardından $50 \mathrm{~m}$ serbest stil yüzme performans1 ölçülmüştür. Statik 1sınma uygulamasında ise $5 \mathrm{dk}$ hafif tempo koşu ardından 2dk yürüyüş ve 1sınma amaçlı $6 \times 50 \mathrm{~m}$ serbest stil yüzme ardından 6 farklı statik germe hareketi uygulanmıştır. Performans öncesinde $3 \mathrm{dk}$ toparlanma süresi verilmiştir. Ardından 50m serbest stil yüzme performansı ölçülmüştür. Dinamik 1sınmada ise kontrol uygulamasında yapılan aktivitelere ek olarak 6 farklı dinamik isınma hareketi uygulanmış ve $50 \mathrm{~m}$ serbest stil yüzme performansı ölçülmüş̧ür. Isınma uygulamaları 3 farklı günde aynı gruba uygulanmıştır. Verilerin analizinde Shapiro Wilk normal dağılıma uygunluk testi, varyans analizi testleri sonucu normal dağılım gösterdiği ve varyansların homojenliği gözlendiğinden tekrarlı ölçümlerde tek yönlü Varyans Analizi testi kullanılmıştır. Fark gözlenen değişkenler için Bonferroni Testi uygulanmıştır. Ölçümler sonucunda dinamik 1sınma protokolü ile diğer isınma protokolleri arasında bir farklılık gözlenmezken, statik 1sınma ve kontrol uygulaması arasında $20 \mathrm{~m}$ performans zamanı ve $30 \mathrm{~m}$ performans zamanı arasında anlamlı bir farklılık bulunmuştur $(\mathrm{p}<0.05)$. Statik 1sınma uygulamalarının performansı artırdığı sonucuna ulaşılmıştır.
\end{abstract}

Anahtar Kelimeler: Isınma, yüzme, statik 1sınma, dinamik 1sınma

\section{The effect of different types of warm-up on $50 \mathrm{~m}$ on swimming performance} Ahmet Emre FAKAZLI ${ }^{1}$, İpek EROĞLU KOLAYIŞ ${ }^{2}$

\begin{abstract}
The present study investigated the impact of three different warm-up routines on $50 \mathrm{~m}$ swimming performance. 17 swimmers (5 female and 12 male swimmers) (Age:13 $\pm 0,99$,

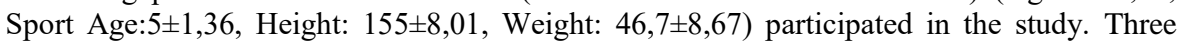
different warm-up practices were administered to the all swimmers on three separate days. In the control implementation, the swimmers did $5 \mathrm{~min}$. jogging, had a $2 \mathrm{~min}$. walk, and they performed $6 \times 50 \mathrm{~m}$ freestyle swimming for warm-up. They did not carry out any static stretching or dynamic warm-up practices. After $3 \mathrm{~min}$. of recovery time, their $50 \mathrm{~m}$ freestyle swimming performance was measured. On the other day, in the stretching implementation, after the $5 \mathrm{~min}$. jogging, $2 \mathrm{~min}$. walk, $6 \times 50 \mathrm{~m}$ freestyle swimming for warm-up, the swimmers also performed six different stretching practices. After $3 \mathrm{~min}$. of recovery time, their $50 \mathrm{~m}$ freestyle swimming performance was measured. On the third day, in the dynamic warm-up implementation, after the usual routines of the control group, they performed six different dynamic warm-up practices, and after $3 \mathrm{~min}$. again their $50 \mathrm{~m}$ freestyle swimming performance was measured. The data were analyzed through the Shapiro-Wilk Test was carried out. Upon finding out normal distribution and homogeneity of the variances as a result of variance analysis test, one-way analysis of variance test was performed. Also, Bonferroni Test was conducted for differential variables. Based on the findings, there was no statistically significant difference between dynamic warm-up practice and other warm-up protocols. The study also indicated that there was a statistically significant difference between the control implementation and static stretching practice at the $20 \mathrm{~m}$ and $30 \mathrm{~m}$, which means that static stretching practices improved swimming performance $(\mathrm{p}<0.05)$.
\end{abstract}

Article Info

Keywords: Warm-up, swimming, static warm-up, dynamic warm-up

${ }^{1}$ Sakarya Üniversitesi, Spor Bilimleri Fakültesi, Rekreasyon Bölümü, Sakarya

${ }^{2}$ Sakarya Üniversitesi, Sağlık Bilimleri Enstitüsü, Antrenörlük Eğitimi Programı, Sakarya

*Bu makale aynı adlı yüksek lisans tezi orijinal araştırmasının makalesidir

Received:07.05.2018

Accepted:16.06.2018

Online Published: 30.09.2018

DOI:10.26453/otjhs.421696

Corresponding Author

Ahmet Emre FAKAZLI 


\section{GíRiș}

Isınma, genel olarak atleti aktiviteye hazırlama ve performansı artırma çalışması olarak kabul edilir. ${ }^{1}$ Isınmanın, kas ve tendon hareketlerini artırdığı, kan akışını hızlandırdığı ve kasların sıcaklığını arttırmak için kullanıldığı yaygın olarak bilinir. ${ }^{2}$ Bunun yanında 1sınma, kasları harekete geçirerek sakatlık riskini azaltır. ${ }^{3}$ Isınma rutinleri hemen hemen her spor dalında antrenman ve yarışma öncesinde kullanılır. ${ }^{4}$ Ancak antrenman ve performans öncesi yapılan ısınma çalışmalarının tam olarak bilimsel temelli olmayıp, antrenörler ve sporcuların bireysel tecrübelerine dayanarak yapıldığı görülmektedir. ${ }^{5} \mathrm{Bu}$ durum, 1sınma türlerinin etkilerinin araştırılmasını ve doğru ısınma yöntemlerinin performans artırımı için kullanımını gerekli kılmaktadır.

Son yıllarda yapılan çalışmalara bakıldığında farklı türde 1sınma rutinlerinin farklı spor dallarında performans üzerine etkilerinin araştırdığı görülmektedir. ${ }^{6,7,8,9}$ İyi bir yüzme performans1 antrenmandan, genetik faktörlerden, bireyin sahip olduğu firsatlardan ve 1sınmadan etkilenebilir. Isınma, atletik performansın en önemli faktörü olarak bilinir. ${ }^{10}$ Isınmanın yüzmede özellikle $200 \mathrm{~m}$ ve üzerindeki mesafelerde pozitif etkisinin olduğu gözlenmiştir. ${ }^{5}$ Isınmanın kısa mesafede yüzme üzerindeki etkilerine bakacak olursak; Romney ve Nethery, kuru alanda yapılan isınma rutinlerinin performansı $\operatorname{artırdiğı~sonucuna~}$ ulaşmışlardır. ${ }^{11} \mathrm{Bu}$ sonuç, Kaya ve ark. tarafindan desteklenmektedir ancak bu çalışmada su içerisinde yapılan ısınmanın performansı daha çok arttırdı̆̆ı gözlenmiştir. ${ }^{12}$ Neiva ve ark. 1sınma sonrasında yüzme performansının arttığı sonucuna ulaşmışlardır. ${ }^{13}$ Ballionis ve ark. 1sınma sonucunda $50 \mathrm{~m}$ yüzme performansının arttığı sonucuna ulaşmışlarıdır. ${ }^{10}$ $\mathrm{Bu}$ sonuçların aksine, Kafkas ve ark. yaptığ çalışmada statik ısınma protokollerinin $50 \mathrm{~m}$ yüzme performansını ciddi seviyede düşürdüğü sonucuna ulaşırken ${ }^{14}$, Moran ve ark. su içerisinde yapılan dinamik ve statik ısınma sonrasında $50 \mathrm{~m}$ performans değerlerinde anlamlı bir fark bulamamışlardır. ${ }^{15} \mathrm{Bu}$ çalışmaya ek olarak, Marinho ve ark. yüzmede çıkış performansını incelendikleri çalışmalarında iki ısınma rutini arasında anlamlı bir farklılık bulunamamıştır. ${ }^{16}$

Çalışmalar gösteriyor ki 1sınmanın yüzmede kısa mesafedeki etkileri tam olarak açık değildir. Isınmanın, kısa mesafede yüzme performans1 üzerinde bir etkisinin olup olmadığına daha iyi cevaplar verebilmek için bu alanda daha fazla bilimsel çalışmaya ihtiyaç duyulmaktadır. Antrenmanın ve yarışmanın her bir safhasında performansı artıracak özel faktörleri belirlemek önemlidir. Sportif performans öncesinde dinamik 1sınma gibi 1lımlı bir seviyeden yüksek yoğunluğa doğru yapılacak istemli kasılmaların, sinir-kas fonksiyonunu aktive ederek güç üretimi ve performansın artacağını düşünülmektedir. Bunun yanında performans öncesinde yapılacak 
olan dinamik aktivite ve statik germe çalışmalar incelenerek çalışmaya adapte uygulamalarının yüzme performansını artıracağı edilmiştir. ${ }^{17,14,13,10,18}$ Isınma protokolleri kuru düşünülmektedir.

$\mathrm{Bu}$ çalışmada farklı 1sınma tekniklerinin $50 \mathrm{~m}$ alanda ve su içerisinde koordineli bir şekilde uygulanmıştır.

yüzme performansı üzerine etkilerinin incelenmesi amaçlanmıştır.

\section{MATERYAL VE METOT}

\section{Araştırma Grubu}

Çalışmaya 5 kı, 12 erkek olmak üzere toplam 17 sporcu katılmıştır. Deneklere ait yaş, boy, spor yaşı ve vücut ağırlığı bilgileri ile ortalama, standart sapma değerleri Tablo 1'de verilmiştir.

Tablo 1. Çalışma Grubunu Demografik Özellikleri

\begin{tabular}{|c|c|c|c|c|c|}
\hline & n & Ort & SS & Min & Max \\
\hline Yaş (yıl) & 17 & 13 & 0,99 & 11 & 15 \\
\hline Spor Yaş1 (yıl) & 17 & 5 & 1,36 & 2 & 7 \\
\hline Boy $(\mathrm{cm})$ & 17 & 155 & 8,01 & 145 & 174 \\
\hline V. A Ăırlığ $1(\mathrm{~kg})$ & 17 & 46,7 & 8,67 & 35 & 66 \\
\hline
\end{tabular}

Araştırmaya katılan sporculara, çalışmanın amacı, statik germe, dinamik 1sınma teknikleri ve protokoller hakkında bilgi verilmiştir. Çalışma süresi boyunca sporcular çalışma haricinde antrenman yapmamışlardır.

Çalışma deneklerin yaşları gereği velilerin onayı alınarak uygulanmış ve gönüllü olur formu imzalatılmıştır.

\section{Verilerin Toplanmast}

$\mathrm{Bu}$ araştırmada, statik germe ve dinamik ısınma yöntemlerinin kullanıldığı 3 farklı 1 sınma protokolü uygulanmıştır. $\mathrm{Bu}$ protokoller çalışmanın amacına uygun olarak farklı

Dinamik ve statik isınma hareketleri 35 sn set aralıkları ile 3 set halinde 30 sn 1 sinma ve 5 sn dinlenme süre aralığı ile uygulanmıştır. ${ }^{15}$ Isınma uygulamaları yaklaşık $10-15 \mathrm{dk}$ arasında sürmüştür. Her isınma protokolü sonrasında performansı öncesi $3 \mathrm{dk}$ dinlenme süresi verilmiştir. Bu süre diğer çalışmalar incelenerek ve yüzülecek mesafe göz önünde bulundurularak belirtilmiștir. ${ }^{10,14}$ Performans başlangıcı (take your mark) komutu ardından elektronik bip sesi ile depar taşından yapılmıştır. 50m serbest stil yüzme performans1, sporcular tarafindan maksimum performans ile uygulanmıştır. Isınma protokolleri toparlanma süreleri göz önünde bulundurularak 48 saat ara ile saat 08.30 ' da uygulanmıştır. ${ }^{10,12}$

Her performans öncesinde havuzdaki su sicaklığı, hava sicaklığı ve nem oranı ölçülmüştür (su sicaklığg $27.30 \pm 0,08^{\circ}$, hava sıcaklığı $28.00 \pm 0,07^{\circ}$, nem oran1 $58.43 \pm$ $0,61 \%)$.

Tablo 2'de kontrol uygulamas1, statik 1sinma yöntemi ve dinamik 1sınma yöntemlerine ilişkin uygulamalar sıra ile verilmiştir.

\section{Veri Toplama Araçları}

Performans ölçümü amaciyla 2 adet kamera (D5300, Nikon) ve 1 adet telefon (6 Plus, iPhone) kullanılmıştır. Kameraların video 
kalitesi ve çekim hızı 1080p 60fps düzeyindedir. Performans sırasında netliğin korunması amacıyla 3D takip modu kullanılmıştır.

Tablo 2. Çalışma Modeli

\begin{tabular}{|c|c|c|}
\hline $\begin{array}{c}\text { Kontrol } \\
\text { Uygulaması }\end{array}$ & $\begin{array}{c}\text { Statik Isınma } \\
\text { Yöntemi }\end{array}$ & Dinamik Isınma \\
\hline $\begin{array}{l}\text { - } 5 \mathrm{dk} \text { hafif tempo } \\
\text { koșu ardından } 2 \\
\mathrm{dk} \text { yürüyüş } \\
\text { - Isınma amaçlı } \\
6 x 50 \mathrm{~m} \text { serbest } \\
\text { stil yüzme } \\
\text { - 50m serbest stil } \\
\text { yüzme } \\
\text { performansı }\end{array}$ & 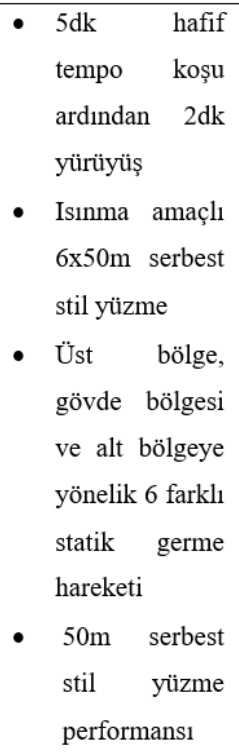 & 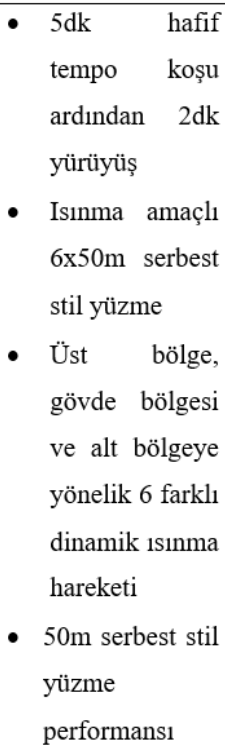 \\
\hline
\end{tabular}

Kameralardan 1 tanesi sporcunun çıkış performansını ölçmek amacıyla sabit bir şekilde konumlandırılmıştır. Buna ek olarak 720p 240fps kalite ve çekim hızını sahip olan telefon ağır çekim modunda çıkış performansını kaydetmek amacıyla sabit bir şekilde konumlandırılmıştır. Çıkış performansının değerlendirilmesinde, depar taşından yapılan start sırasında topukların depar taşından ayrılıp, ellerin suya girişi arasındaki kare sayısı sayılarak bir kare için geçen süre $(1 / 240 \mathrm{sn})$ ile çarpılmış ve çıkış süresi hesaplanmıştır. Diğer kamera ise havuzun tamamını görecek şekilde konumlandırılmıştır. $10 \mathrm{~m}, 20 \mathrm{~m}, 30 \mathrm{~m}, 40$ ve $50 \mathrm{~m}$ performanslarını ölçmek amacıyla havuz kenarına beyaz şeritler çekilmiştir. Bu kamera ile $10 \mathrm{~m}, 20 \mathrm{~m}, 30 \mathrm{~m}, 40$ ve $50 \mathrm{~m}$ geçiş sürelerinin yanı sıra 50m' deki toplam kulaç sayısı belirlenmiştir. Performanslar 50m'lik olimpik yüzme havuzunda uygulanmıştır (Sakarya Yüzme Havuzu). Buna ek olarak, vücut ağırlığı ve boy ölçümü için boy ölçerli tartı (RGZ, Swan) kullanılmıştır (Ağırlık ölçüm hassasiyeti $0,1 \mathrm{~kg}$, boy ölçüm hassasiyeti $0,01 \mathrm{~cm}$ ).

\section{Istatistiksel Analiz}

Çalışmadan elde edilen verilerin analizinde SPSS 20.0 programında Shapiro Wilk normal dağılıma uygunluk testi, varyans analizi testleri sonucu normal dağılım gösterdiği ve varyansların homojenliği gözlendiğinden tekrarlı ölçümlerde tek yönlü Varyans Analizi testi kullanılmıştır. Fark gözlenen değişkenler için Bonferroni PostHoc testi uygulanmıştır. Anlamlılık düzeyi ( $\alpha) \quad 0.05$ olarak belirlenmiştir.

\section{BULGULAR}

Çalışmaya katılan deneklerin 3 ısınma protokolü sonucunda elde edilen çıkış performansı, kulaç sıklığ $1,10 \mathrm{~m}, 20 \mathrm{~m}, 30 \mathrm{~m}, 40$ ve $50 \mathrm{~m}$ performans verilerinin analizi Tablo 3'te verilmiştir. Elde edilen bulgular sonucunda, dinamik isınma protokolü bakımından diğer isınma protokolleri arasında bir farklılık bulunmazken, $20 \mathrm{~m}$ performansı bakımından statik ısınma ve kontrol uygulaması arasında istatistiksel anlamda farklılık bulunmuştur $(\mathrm{p}<0.05)$. Buna ek olarak 30m performansı bakımından da statik ısınma 
ve kontrol uygulaması arasında fark bulunmuştur $(\mathrm{p}<0.05)$.

Tablo 3. Analiz sonucu elde edilen bulgular

\begin{tabular}{|c|c|c|c|c|c|}
\hline & & Ort & SS & $\mathbf{F}$ & p \\
\hline \multirow{3}{*}{$\begin{array}{c}\text { Kulaç Sayıs1 } \\
\text { (adet) }\end{array}$} & Kontrol uxg & 52 & 6,35 & \multirow{3}{*}{2.572} & \multirow{3}{*}{0.092} \\
\hline & Statik Isınma & 53 & 5,92 & & \\
\hline & Dinamik Isınma & 51 & 5,50 & & \\
\hline \multirow{3}{*}{ Çıkış Performansı (sn) } & Kontrol yxg & 0,75 & 0,18 & \multirow{3}{*}{0.045} & \multirow{3}{*}{0.956} \\
\hline & Statik Isınma & 0,76 & 0,13 & & \\
\hline & Dinamik Isınma & 0,76 & 0,16 & & \\
\hline \multirow{3}{*}{$10 \mathrm{~m}$ Performans (sn) } & Kontrol yXg & 5,15 & 0,46 & \multirow{3}{*}{0.101} & \multirow{3}{*}{0.814} \\
\hline & Statik Isınma & 5,11 & 0,36 & & \\
\hline & Dinamik Isınma & 5,14 & 0,49 & & \\
\hline \multirow{3}{*}{$20 \mathrm{~m}$ Performans (sn) } & Kontrol uxg & 12,79 & 1,28 & \multirow{3}{*}{6.511} & \multirow{3}{*}{$0.004^{*}$} \\
\hline & Statik Isınma & 11,63 & 0,90 & & \\
\hline & Dinamik Isınma & 11,94 & 1,58 & & \\
\hline \multirow{3}{*}{ 30m Performans (sn) } & Kontrol yxg & 19,28 & 2,22 & \multirow{3}{*}{4.061} & \multirow{3}{*}{$0.027^{*}$} \\
\hline & Statik Isinma & 18,28 & 1,40 & & \\
\hline & Dinamik Isınma & 18,54 & 1,70 & & \\
\hline \multirow{3}{*}{ 40m Performans (sn) } & Kontrol uxg & 27,04 & 2,22 & \multirow{3}{*}{1.496} & \multirow{3}{*}{0.239} \\
\hline & Statik Isınma & 27,01 & 2,18 & & \\
\hline & Dinamik Isınma & 26,49 & 2,57 & & \\
\hline \multirow{3}{*}{$50 \mathrm{~m}$ Performans (sn) } & Kontrol yxg & 35,17 & 2,81 & \multirow{3}{*}{3.182} & \multirow{3}{*}{0.055} \\
\hline & Statik Isınma & 34,99 & 2,94 & & \\
\hline & Dinamik Isınma & 34,43 & 3,23 & & \\
\hline
\end{tabular}

Qrt: ortalama, SS: standart sapma, ${ }^{*} p<0.05$

Bulgularda gösteriyor ki bu çalışmada su içerisinde ve karada koordineli bir şekilde uygulanan statik 1sınma rutini yüzmede 20 ve 30 m de performansı olumlu etkilemiştir.

\section{TARTIŞMA VE SONUÇ}

$\mathrm{Bu}$ çalışmanın amacı farklı 1sınma tekniklerinin yüzücülerde $50 \mathrm{~m}$ yüzme performansı, çıkış performansı ve kulaç sıklığı üzerini etkisini araştırmaktır. Bu çalışmaya yaşları 11-15 olan 17 gönüllü kız ve erkek yüzücüler katılmıştır. Çalışmada aynı gruba 48 saat ara ile 3 farklı sınma protokolü uygulanmış ve performans ölçümü sonucunda hangi 1sınma protokolünün yüzücülerde performans açısından daha yararlı olduğunun tespit edilmesi amaçlanmıştır. Performans sonrasinda elde edilen bulgular sonucunda statik isınma protokolünün $20 \mathrm{~m}$ ve 30m performans zamanını olumlu etkilediği gözlenmiştir $(\mathrm{p}<0.05)$.

Isınma kaslardaki sıcaklık artışının yanında birçok fizyolojik ve metobolik değişikliklere sebep olurken, bu değişiklikler sporcunun performansına etki eder. ${ }^{19}$ Isınma sporcuyu sakatlıktan korur ve fiziksel performansı artırır. $^{20}$ Bunun yanında, 1sınma eklemlerin yüklenme karşısındaki direncini geliştirir ve kalp ve kan dolaşımı sistemini pozitif yönde etkiler. $^{21}$ Isınmanın yüzmede $200 \mathrm{~m}$ ve üzerindeki mesafelerde pozitif etkisinin olduğu bilinirken, $200 \mathrm{~m}$ ve altındaki mesafelerde pozitif etkisi $\% 1$ den daha azdır. ${ }^{5}$ Araştırmacılar yüzmede kısa mesafede 1sınmanın performans veya metabolizma üzerindeki etkilerini araştırmışlardır. ${ }^{10,12,18,11} \mathrm{Bu}$ çalışmalara rağmen ısınmanın kısa mesafe yüzme üzerindeki etkileri tam olarak açık değildir.

Isınmanın yüzme üzerindeki etkilerini inceleyen çalışmalara bakacak olursak; Moran ve ark. dinamik 1sınma ve statik germe uygulamalarının 50m yüzme performans zamanını inceledikleri çalışmada iki protokol sonrasında 25 ve $50 \mathrm{~m}$ performans zamanı arasında anlamlı bir farklılık bulunmamıștır. ${ }^{15}$ Marinho ve ark. 1Sınmanın yüzücülerde çıkış performansını incelediği 
çalışmada, iki ısınma rutini arasında anlamlı bir farklılık bulunmamıştır. ${ }^{16} \mathrm{Bu}$ sonuç çıkış performansı bakımından bu çalışmayla tutarlı sonuçlar vermiştir. Neiva ve ark. 1sınmanın kadınlarda 50m yüzme performansını incelediği çalışmada ısınmasız ve düzenli ısınma uygulamasının 25 ve 50 m performansı üzerinde anlamlı bir etkisinin olmadığı sonucuna ulaşılmıştır. ${ }^{22}$ Performansta negatif sonuçlar veya değişmeyen sonuçlar için şu açıklamalar yapılabilir. Isınmanın düşük yoğunlukta oluşu ve dolayısıyla katılımcıda gerekli değişikliklere sebep olmaması ya da çok yoğun olup yorgunluğa sebep olması ve egzersizden önce yeterince toparlanmaya izin verilmemiş olması bu sonuçlara sebep olabilir. ${ }^{19}$

Isınmanın kısa mesafede performans üzerinde etkisini bulan çalışmalar da vardır; Kaya ve ark. 1Sınmanın erkek yüzücülerin $50 \mathrm{~m}$ performansını incelediği çalışmada, su içerisinde yapılan 1sınma protokolünün performans1 olumlu etkilediği sonucuna ulaşmışlardır. ${ }^{12} \mathrm{Bu}$ çalışma 1sınma rutini anlamında yapılan çalışmayı desteklemektedir. Aynı çalışmada kuru alanda uygulanan 1sınma protokolünün, su içerisinde uygulanan 1sinma rutinine kiyasla performans1 daha az artırsa da pozitif yönde etkilediği sonucuna ulaşılmıştır. Kuru alanda yapılan ısınmanın yüzücülerde performansı artırdığı Romney ve Nethery tarafindan da desteklenmektedir. ${ }^{11}$ Marinho ve ark. dinamik 1sınma ve statik 1sınma aktivitelerinin $60 \mathrm{~m}$ sprint performansını üzerindeki etkisini inceledikleri çalışmada statik 1sınmanın ilk 20 ve $60 \mathrm{~m}$ performans zamanını $\% 1.7$ artırdı ğ sonucuna ulaşmışlardır. ${ }^{23} \mathrm{Bu}$ çalışma mevcut çalışmayı desteklemektedir. Elde edilen bulgular ve diğer güncel çalışmalar incelendiğinde şu yorumlar yapılabilir. $\mathrm{Bu}$ çalışmada statik ısınma öncesinde $5 \mathrm{dk}$ koşu ve 2dk dinlenme ardından isınma amaçlı 6x50m serbest stil yüzme uygulanmıştır. Statik germeden önce ya da sonra dinamik aktiviteler yapmak statik germenin performans üzerindeki negatif etkileri azaltabilir. İstenmeyen kas etkisini ve ilgili sinir etkilerini tersine çevirdiği söylenebilir. ${ }^{24}$ Ek olarak, bu çalışmada katılımcilar statik germe hareketleri sonucunda meydana gelen kas hareket genişliğinden yararlanmış olabilirler. Sonuç olarak ısınmada statik germe hareketleri dinamik aktivitelere tamamlayıcı olarak kullanıldığında performans anlamında pozitif etkiler gösterebilir.

\section{Öneriler}

Tüm çalışmalara rağmen 1sınmanın kısa mesafede yüzme üzerindeki ideal yapısı ve etkisi tam olarak açık ve net değildir. Bunun sebebinin yüzme ortamından kaynaklandığı söylenebilir. Kuru alan olmayıșı, sıcaklık, nem gibi faktörler 1sınmanın yüzme üzerindeki etkilerini araştırmayı zorlaştırmaktadır. ${ }^{5}$ Aynı zamanda havuzdaki sicaklık ve nem gibi faktörler de sporcu metabolizmasını performans bakımından etkileyebilir. Isınmanın özellikle kısa mesafede etkilerini araştırmak için çalışmalar genişletilmeli ve detaylandırılmalıdır. 
Performans zamanının yanı sıra fizyolojik parametreler de detaylı bir şekilde incelenmelidir.

\section{KAYNAKLAR}

1. Hedrick A. Physiological responses to warm up. National Strength and Conditioning Journal. 1992;14(5):25-27.

2. Smith CA. The warm up procedure: To stretch- A brief review. The journal of Orthopaedic and Sports Physical Therapy. 2004; 19:12-17.

3. Woods K, Biskop P, Jones E. Warm up and streching in the prevention of muscular injury. Sports Medicine. 2007;37(12):1089-1099.

4. Ekstrand J, Gillquist J, Liljiedahl SO. Prevention of soccer injuries: supervision by doctor and physiotherapist. Am J Sports Med 1983; 11:116120.

5. Neiva HP, Marques MC, Barbosa TM, İzquierdo M, Marinho DA. Warm-Up Performance in Competitive Swimming. Sports Med. 2014;44:319-330.

6. McMilian DJ, Moore JH, Hatler BS, Taylor C. Dynamic ve static-stretching warm up: The effect on power and agility performance. Journal of Strength and Conditioning Research. 2006;20(3):492-499.

7. Szymanski DJ, Beiser EJ, Bassett KE ve diğerleri. Effect of various warm up devices on bat velocity of intercollegiate baseball players. J Strength Cond Res. 2011;25(2):287-292.

8. Eken Ö. Judocularda farklı 1sinma protokollerinin, $30 \mathrm{~m}$ sürat, esneklik, dikey sıçrama, kuvvet, denge ve anaerobik güç performansları üzerine akut etkisinin incelenmesi: Spor Sağlık Bilimleri Anabilim Dali, Ege Üniversitesi; 2015.

9. Paradisis GP, Pappas PT, Theodorou AS, Zacharogiannis EG, Skordilis EK, Smirniotou AS. Effects of static and dynamic stretching on sprint and jump performance in boys and girls. The Journal of Strength \& Conditioning Research. 2014;28(1):154-160.

10.Ballionis G, Nepocatych S, Ellis CM, Richardson MT, Neggers YH, Bishop PA. Effects of Different Types of Warm-up on Swimming Performance, Reaction Time ve Dive Distance. Journal of Strength and Conditioning Research. 2012;33(7):483-498.

11.Romney NC, Nethery VM. The effect of swimming and dryland warm-ups on 100-yard Freestyle performance in collegiate swimmers. J Swim Res. 1993;9:5-9.

12.Kaya F, Erzeybek MS, Biçer B, Meral T. Effects of in-water and dryland warm-ups on 50-meter Freestyle performance in cild swimmer. SHS Web of Conferences. 2017;37: 01047.

13. Neiva H, Morouço P, Silva AJ, Marques MC, Marinho DA. The effect of warm up on tethered front crawl swimming forces. Journal of Human Kinetics (Special İssue). 2011:113-119.

14.Kafkas AŞ, Eken Ö, Çınarlı FS, Kafkas ME. Acute effect of static warm up duration on 50 meter Freestyle and Breaststroke performance. Journal of Atletic Performance and Nutrition. 2016;3(2):1-10.

15.Moran MP, Whitehead JR, Guggenheimer JD, Brinkert RH. The effects of Static Stretching Warm up Versus Dynamic Warm up on Sprint Swim Performance. J Swimming Research. 2014:22-21.

16. Marinho DA, Marques MC, Louro H, Comceiçao AT, Espata MA, Neiva HP. Effect of Different 
Warm up İntensities on Swimming Starts Performances. NSCA IV İnternational Conference. 2014;109.

17.Turan S. Farklı 1sınma yöntemlerinin okçulukta atı̧̧ performansına etkisi: Eğitim Bilimleri Enstitüsü, Sakarya Üniversitesi; 2016.

18.Agopyan A, Bozdoğan FS, Tekin D, Kucuk Yetkin M, Gun Guler C. Acute effects of static stretching exercises on short distance flutter kicking time in child swimmers. İnternational Journal of Performance Analysis in Sport. 2012;12:484-497.

19.Bishop D. Warm up II: Performance changes following active warm up and how to structure the warm up. Sport Med. 2003;33(7): 483-498.

20.Norris CM. The complete guide to stretching. London: A \& C Black; 1999.
21.Sevim Y. Basketbolda Kondisyon Antrenman1. Ankara: Bağırgan Yayın evi; 2010.

22.Neiva HP, Marques MC, Bacelar L, Moinhos N, Morouço PG, Marinhlo DA. Warm up effect in short distance swimming performance. Annals of Research in Sport and Physical Activity. 2012: 83-94.

23. Marinho DA, Gil MH, Marques MC, Barbosa TM, Neiva HP. Comlementing warm-up with streching routinese: Effects in sprint performance. Sports Medicine İnternational Open. 2017:E101-E106.

24.Little T, Williams AG. Effects of differential streching protokols during warm up on high speed motor capacities in Professional soccer players. J Strength Cond Res. 2006;20:203-207. 
Tablo 1. Araştırma Grubunu Demografik Özellikleri

\begin{tabular}{lccccc}
\hline & n & Ort & SS & Min & Max \\
\hline Yaş (yıl) & 17 & 13 & 0,99 & 11 & 15 \\
Spor Yaşı (yıl) & 17 & 5 & 1,36 & 2 & 7 \\
Boy (cm) & 17 & 155 & 8,01 & 145 & 174 \\
V. Ağırlığ (kg) & 17 & 46,7 & 8,67 & 35 & 66 \\
\hline
\end{tabular}

Ort: ortalama, SS: standart sapma, Min: En küçük, Max: en büyük

Tablo 2. Çalışma Modeli

\section{Kontrol Uygulaması}

\section{Statik Isınma Yöntemi}

\section{Dinamik Isınma}

\section{Yöntemi}

- 5dk hafif tempo koşu • 5dk hafif tempo koşu ardından $2 \mathrm{dk}$ yürüyüş $\quad$ ardından $2 \mathrm{dk}$ yürüyüş

- $5 \mathrm{dk}$ hafif tempo koşu ardından $2 \mathrm{dk}$ yürüyüş

- Isınma amaçli 6x50m serbest stil yüzme

- $50 \mathrm{~m}$ serbest stil yüzme performans 1

- Isınma amaçli 6x50m

- Isınma amaçli 6x50m serbest stil yüzme serbest stil yüzme

- Üst bölge, gövde bölgesi ve • Üst bölge, gövde bölgesi ve alt bölgeye yönelik 6 farklı alt bölgeye yönelik 6 farklı statik germe hareketi dinamik 1sınma hareketi

- $50 \mathrm{~m}$ serbest stil yüzme $-50 \mathrm{~m}$ serbest stil yüzme performans 1 
Tablo 3. Analiz sonucu elde edilen bulgular
Ort
SS
$\mathbf{F}$
p

\begin{tabular}{|c|c|c|c|c|c|}
\hline \multirow{3}{*}{$\begin{array}{l}\text { Kulaç Sayısı } \\
\text { (adet) }\end{array}$} & Kontrol uyg. & 52 & 6,35 & \multirow{3}{*}{2.572} & \multirow{3}{*}{0.092} \\
\hline & Statik Isınma & 53 & 5,92 & & \\
\hline & Dinamik Isınma & 51 & 5,50 & & \\
\hline \multirow{3}{*}{ Çıkış Performansı (sn) } & Kontrol uyg. & 0,75 & 0,18 & \multirow{3}{*}{0.045} & \multirow{3}{*}{0.956} \\
\hline & Statik Isınma & 0,76 & 0,13 & & \\
\hline & Dinamik Isınma & 0,76 & 0,16 & & \\
\hline \multirow{3}{*}{ 10m Performans (sn) } & Kontrol uyg. & 5,15 & 0,46 & \multirow{3}{*}{0.101} & \multirow{3}{*}{0.814} \\
\hline & Statik Isınma & 5,11 & 0,36 & & \\
\hline & Dinamik Isınma & 5,14 & 0,49 & & \\
\hline \multirow{3}{*}{ 20m Performans (sn) } & Kontrol uyg. & 12,79 & 1,28 & \multirow{3}{*}{6.511} & \multirow{3}{*}{$0.004 *$} \\
\hline & Statik Isınma & 11,63 & 0,90 & & \\
\hline & Dinamik Isınma & 11,94 & 1,58 & & \\
\hline \multirow{3}{*}{ 30m Performans (sn) } & Kontrol uyg. & 19,28 & 2,22 & \multirow{3}{*}{4.061} & \multirow{3}{*}{$0.027 *$} \\
\hline & Statik Isınma & 18,28 & 1,40 & & \\
\hline & Dinamik Isınma & 18,54 & 1,70 & & \\
\hline \multirow{3}{*}{ 40m Performans (sn) } & Kontrol uyg. & 27,04 & 2,22 & \multirow{3}{*}{1.496} & \multirow{3}{*}{0.239} \\
\hline & Statik Isınma & 27,01 & 2,18 & & \\
\hline & Dinamik Isınma & 26,49 & 2,57 & & \\
\hline \multirow{3}{*}{ 50m Performans (sn) } & Kontrol uyg. & 35,17 & 2,81 & \multirow{3}{*}{3.182} & \multirow{3}{*}{0.055} \\
\hline & Statik Isınma & 34,99 & 2,94 & & \\
\hline & Dinamik Isınma & 34,43 & 3,23 & & \\
\hline
\end{tabular}

Ort: ortalama, SS: standart sapma, * $p<0.05$ 